\title{
Why care about long term testosterone deficiency? \\ Osteopenia and osteoporosis: Bone fractures, health and social consequences
}

Robert G Josse MD FRCP(UK) FRCPC

RG Josse. Why care about long term testosterone deficiency? Osteopenia and osteoporosis: Bone fractures, health and social consequences. J Sex Reprod Med 2001;1(2):91-95.

Osteoporotic fractures in men have been, until recently, a neglected health problem, but this area is now the subject of renewed interest and investigation. Osteoporosis, once thought, inappropriately, to be an inevitable consequence of aging, is now assuming increasing importance, especially in women, because of the morbidity and mortality associated with fractures, and the burgeoning public health burden that this represents. However, more recently it has also been recognized that men lose bone density with advancing age and are also subject to osteoporotic fractures. One in eight men older than the age of fifty years has an osteoporotic fracture, and some $30 \%$ of hip fractures, representing the greatest health care burden, occur in men. Moreover, the mortality rate after a hip fracture is greater in men than women. While osteoporosis in men and women have many similarities, there are some interesting differences. Present therapies, while not entirely empirical, have been guided by studies in women, and carefully controlled, randomized antifracture clinical trials in men are required.

Key Words: Bone fractures; Cardiovascular safety; Health consequences; Lipid profile; Osteopenia; Osteoporosis; Social consequences

\section{Pourquoi s'intéresser au déficit en testostérone à long terme? Ostéopénie et ostéoporose : frac- tures, santé et conséquences sociales}

RÉSUMÉ : Les fractures ostéoporotiques chez l'homme ont été, jusqu'à tout récemment, un problème de santé négligé, mais elles font maintenant l'objet d'un intérêt renouvelé et de recherches. On croyait, à tort, que l'ostéoporose était une conséquence inévitable du vieillissement; maintenant, elle gagne de l'importance, surtout chez les femmes, en raison de la morbidité et de la mortalité associées aux fractures et au fardeau financier que ces dernières imposent au système de santé public. Cependant, on a constaté récemment que la déperdition osseuse se produit aussi chez les hommes vieillissants et qu'ils sont sujets aux fractures ostéoporotiques. Un homme sur huit, âgé de plus de 50 ans, subit une fracture ostéoporotique et environ $30 \%$ des fractures de la hanche, celles qui imposent le plus lourd tribut au système de santé, touchent les hommes. De plus, le taux de mortalité après une fracture de la hanche est plus élevé chez les hommes que chez les femmes. Même si l'ostéoporose chez les hommes et les femmes présente de nombreux points communs, elle comporte également certaines différences. Les formes actuelles de traitement, bien qu'elles ne soient pas tout à fait empiriques, reposent sur des études menées chez les femmes; aussi des essais cliniques soigneusement contrôlés, avec hasardisation, sur des traitements « antifracture » s'imposent-ils chez les hommes.

Professor of Medicine, University of Toronto and Chief, Division of Endocrinology and Metabolism, St Michael's Hospital Correspondence: Dr Robert Josse, 61 Queen Street East, Toronto, Ontario M5C 2T2. Telephone 416-867-7455, fax 416-867-3696, e-mail josser@smh.toronto.on.ca 
$\mathrm{O}$ steoporosis, once thought, inappropriately, to be an inevitable consequence of aging, is now assuming increasing importance, especially in women, because of the morbidity and mortality associated with fractures, and the burgeoning public health burden that this represents. However, more recently it has also been recognized that men lose bone density with advancing age and are also subject to osteoporotic fractures. One in eight men older than age 50 years has an osteoporotic fracture, and some $30 \%$ of hip fractures, representing the greatest health care burden, occur in men. Moreover, the mortality rate after a hip fracture is greater in men than women. Osteoporotic fractures in men have been, until recently, a neglected health problem, but this area is now the subject of renewed interest and investigation.

\section{EPIDEMIOLOGY OF OSTEOPOROSIS AND FRACTURES IN MEN}

Much less is known about the epidemiology of osteoporosis and osteoporotic fractures in men than women, nor is much known about male osteoporosis in different populations and ethnic groups. Interestingly, men have more fractures than women early in life, probably as a result of trauma. However, around the age of 50 to 60 years, this pattern is reversed, with fragility fractures of the vertebrae, wrist, arm, humerus and elsewhere more common in women. In the Rochester Epidemiology Project in Minnesota, United States and the Dubbo Osteoporosis Epidemiology Study in Australia, the lifetime fracture risks beyond the ages of 50 and 60 years, respectively, were estimated (Table 1). Of the approximately 1.7 million hip fractures worldwide in 1990, about one-third occurred in men, and the mortality rate associated with hip fracture in elderly men older than age 75 years was $30 \%$ versus $9 \%$ for women. It is thought that a greater number of comorbid conditions at the time of fracture contribute to the increased mortality risk.

Vertebral fractures were considered uncommon in men, and most were thought to be related to trauma that occured

\section{TABLE 1}

\section{Osteoporosis in men}

\begin{tabular}{lc}
\hline & Risk (\%) \\
\hline Rochester Epidemiology Project* & \\
Estimated lifetime fracture risk at age 50 years & 6.0 \\
$\quad$ Proximal femur & 5.0 \\
$\quad$ Clinical vertebral & 2.5 \\
$\quad$ Distal forearm & 13.1 \\
$\quad$ Any of the above & \\
Dubbo Osteoporosis Epidemiology Study ${ }^{\dagger}$ & \\
Lifetime atraumatic fracture risk & 25.6 \\
60 years of age & 20.6 \\
70 years of age & 9 \\
80 years of age & \\
\hline
\end{tabular}

*Data from reference $8 ;{ }^{+}$Data from reference 9 earlier in life. However, recent information suggests that the incidence of clinically apparent vertebral fractures is about half that of women. In fact, in persons older than age 65 years in the Dubbo study, the prevalence of spine fractures was similar for men and women (between 10\% and 20\%). In the European Vertebral Osteoporosis Study, similar data were obtained when the age-standardized prevalence of vertebral deformity was estimated for men and women (around $12 \%$ to $20 \%$ ).

In summary, by age 80 years, one in 10 men has experienced a fracture. Hip, spine and humerus fractures increase with age, and there is a fivefold increase in multiple fractures in men older than 75 years compared with those in their early 60 s (Figure 1). Recently updated estimates for men suggest an $11 \%$ prevalence of hip fractures compared with $23 \%$ for women and an associated 3.2-fold increase in mortality for men versus a 2.2-fold increase for women (Figure 2). For vertebral fractures, there is a similar prevalence in men and women between the ages of 50 and 80 years. Very recent data have suggested a 2.4-fold increase in mortality with vertebral fractures, and the mortality rate is higher in men than women (the relative five-year survival rate is 0.84 in women and 0.72 in men).

\section{ETIOLOGY AND PATHOGENESIS}

Osteoporosis in men is not a homogenous entity with a single causative factor. Rather, it is the result of genetic and environmental interactions influencing, among other things, peak bone mass, bone size and microarchitecture.

According to Seeman, the bone in men is less fragile compared with women because there is a higher peak bone mass and larger size (cross-sectional area); there is less bone loss as a percentage of the peak bone mass in men; trabecular thinning is secondary to reduced bone formation rather than trabecular plate perforation and loss of connectivity (giving rise to increased weakness) as occurs in women; there is less cortical bone thinning due to a reduced extent of endocortical resorption and, in men, greater periosteal bone formation; and, there is less intracortical porosity in men. All of these features give rise to the sex differences in fragility between men and women. Moreover, longitudinal studies have shown that although men do not have an equivalent accelerated phase of bone loss to that experienced by women during menopause, there is an increase in bone loss with age (greater in trabecular bone than cortical bone), which can reach about $1 \%$ per year in older men. Interestingly, the bone loss in men occurs primarily through diminished bone formation. While endocortical bone resorption occurs in both men and women (greater in women than men), subperiosteal bone formation is greater in men than women. This increases the outer diameter of the axial and appendicular skeleton. The net result is a relative maintenance of cortical thickness in men compared with women and, in addition, an increase in the diameter of male long bones, which helps to prevent fracture by conferring an additional mechanical advantage and increased strength to the bone. 


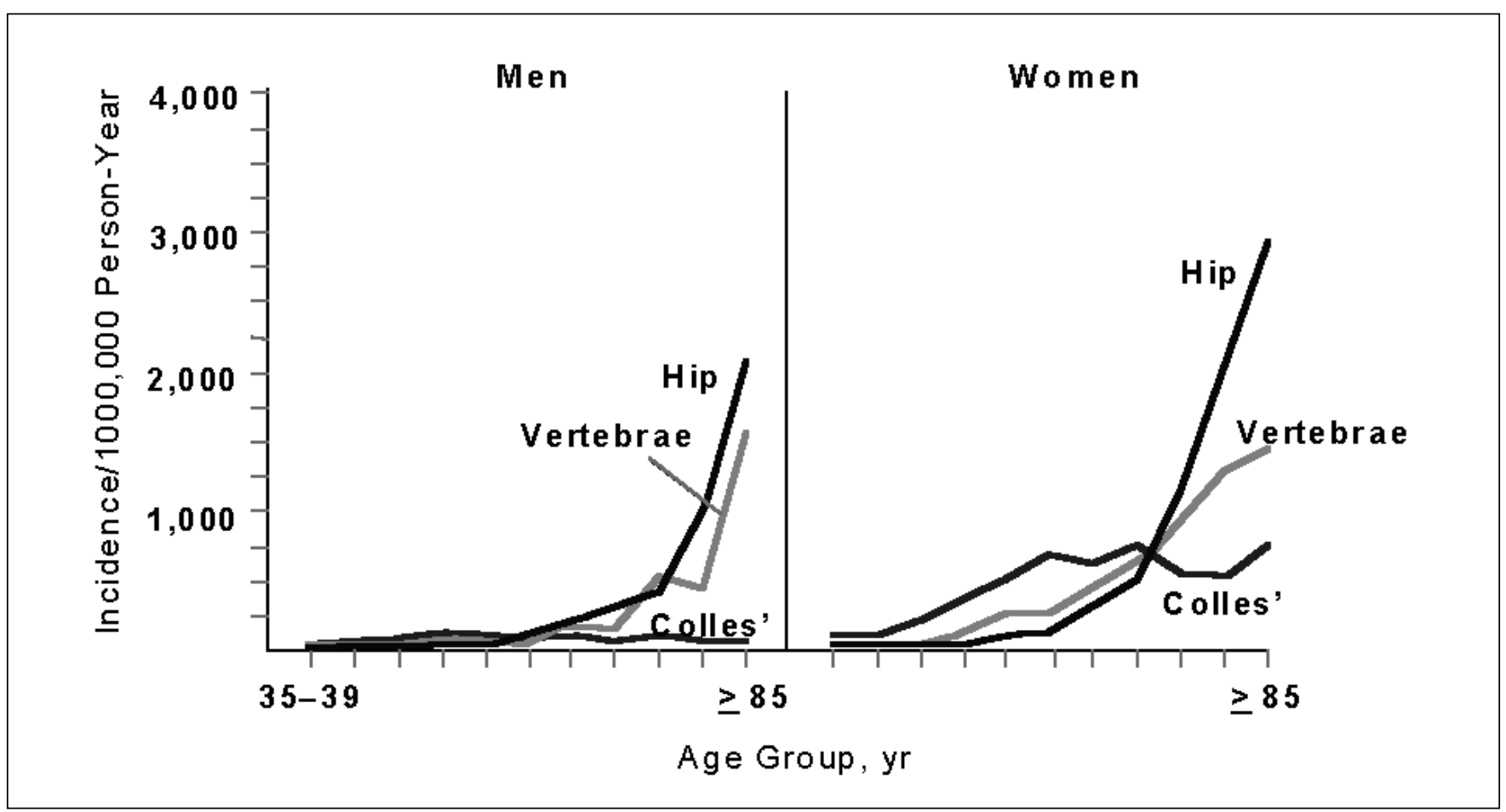

Figure 1) Fractures as a function of age. Hip fracture incidence rates increase exponentially with age, five years later than in women. Adapted from J Bone Miner Res 1992;7:221-227 with permission of the American Society For Bone and Mineral Research

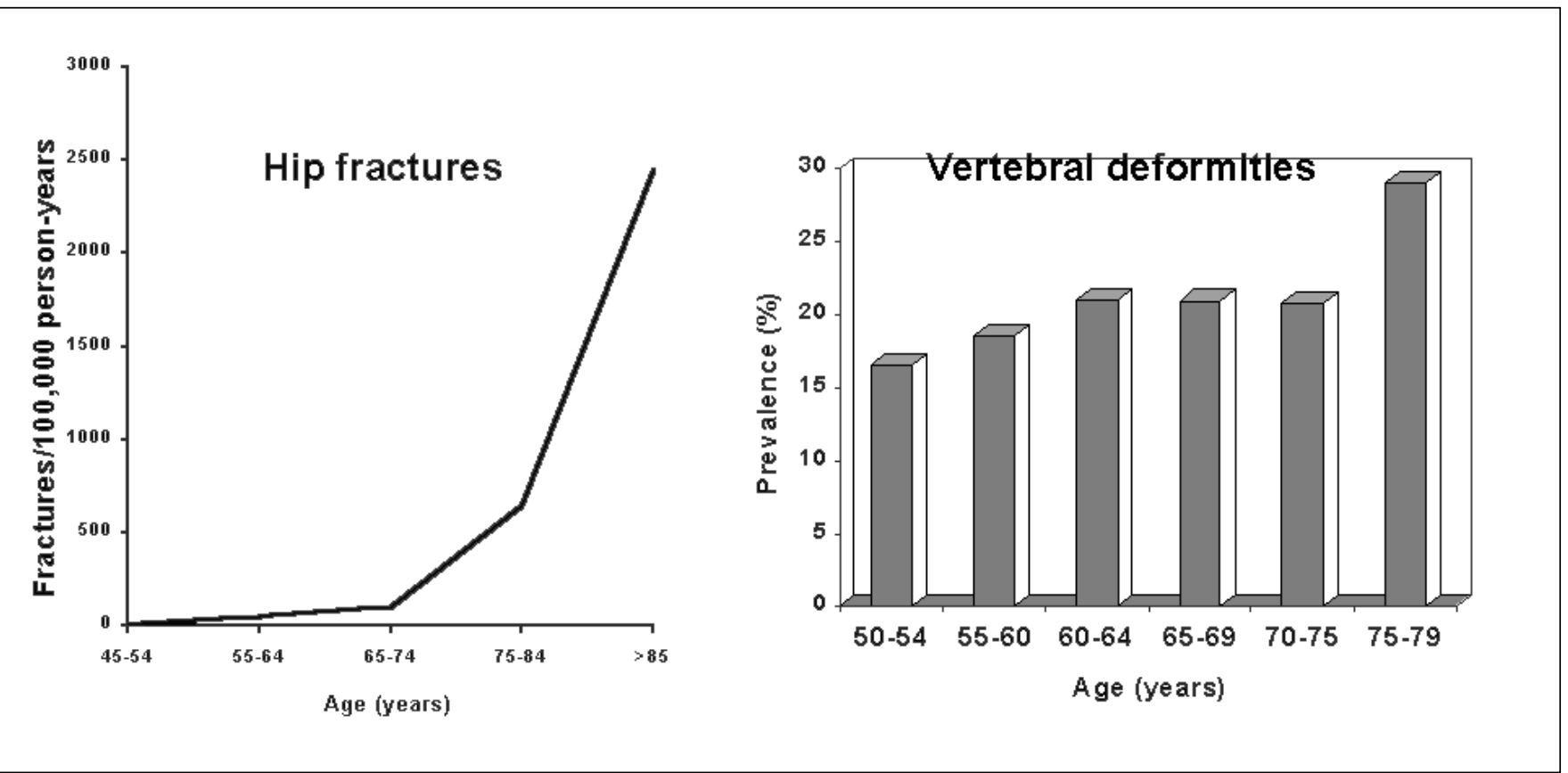

Figure 2) Hip fractures and deformities in men. American expenditures for osteoporotic fractures in men in 1995 were about $\$ 2.7$ billion. Adapted from J Bone Miner Res 1996;11:1010-1018 with permission of the American Society for Bone and Mineral Research

\section{BONE MINERAL DENSITY, AND RISK FACTORS FOR OSTEOPOROSIS AND FRACTURE}

The definition of osteoporosis proposed by the World Health Organization Expert Panel in 1994 was based on data from postmenopausal white women. Whether these same criteria can be used for defining osteoporosis in men is a moot point. Areal bone mineral density when measured using dual-energy x-ray absorptiometry is higher in men than women, but volumetric density (as identified by quantitative computed tomography) is similar between the sexes. Analysis of fracture risk has been complicated by these differences in men and women. Cross-sectional studies have shown lower bone density in men with fractures compared with those without fractures. Yet, men experience 


\section{TABLE 2}

\section{Some risk factors for osteoporotic fractures in men}

\begin{tabular}{l} 
Decreased BMD \\
Decreased BMI \\
Previous fracture \\
Height loss \\
Physical inactivity \\
Muscle weakness (especially quadriceps) \\
Higher body sway \\
Falls \\
Comorbidity \\
Hypogonadism (testosterone deficiency) \\
Alcohol abuse \\
Smoking \\
Corticosteroid use \\
Psychotropic drugs \\
Decreased vitamin D \\
COL 1 A-1 gene polymorphism \\
\hline
\end{tabular}

fractures at a higher bone density than women. However, after adjusting for bone size, men and women seem to fracture at similar bone density values and sex-specific $\mathrm{T}$ scores of bone density. Because there are few studies that have attempted to relate bone density changes to eventual fracture risk, one cannot be certain about the implications of bone density levels or the definition of a fracture threshold. Nevertheless, the probability of fracture decreases as bone density increases. Bone mineral density does seem to predict fracture in men, and men and women have equivalent risks of fracture for equivalent bone mineral density levels. At present, the bone mineral density modus operandi is to use a similar approach for men and women, applying the -1 and -2.5 standard deviation thresholds ('T scores' based on the density levels in young normal male individuals) to identify osteopenia and osteoporosis.

As with women, the etiology of male osteoporosis can be divided into primary (or idiopathic), which accounts for $40 \%$ for $50 \%$ of cases, and secondary causes. The most common secondary causes are glucocorticoid use, hypogonadism and excess alcohol intake. The risk factors for osteoporosis and fractures are multifactorial (Table 2). The sex hormones, both androgens and estrogens, are important for normal bone development and retain this importance throughout life. Several interesting experiments of nature have emphasized the importance of both testosterone and estrogen in the development of the male skeleton and its lifelong maintenance. Some men were identified with mutations in the gene for the aromatase enzyme, which converts testosterone to estrogen, while other men were found to have genetic mutations leading to the absence of the estrogen receptor. As expected, in men with the aromatase enzyme defect, estrogen (but not testosterone) treatment resulted in an improvement in bone density. There was no such improvement among men with mutations in the estrogen receptor when given estrogen. It appears that both estrogen and androgen are necessary for peak bone mass development in the male skeleton, and both are required for optimal skeletal growth. Moreover, it seems that testosterone is necessary for the periosteal bone growth that occurs with age, giving rise to greater cortical width and bones of larger diameter.

Interestingly, however, in older men, cross-sectional studies have not been able to show a consistent association between testosterone levels and bone density, whereas low estradiol levels are strongly associated with low bone mass. In addition, in some studies of testosterone therapy in older men with osteoporosis, bone density increases were better correlated with changes in estradiol than changes in testosterone. Although the data are still somewhat confusing and more studies are required, sex hormone deficiency is an important cause of bone loss in men. Testosterone levels do fall with age for a number of reasons, although it is not an abrupt loss similar to the fall in estrogen levels during menopause in women. However, no studies have identified reliably the level of serum testosterone (or estradiol) that may be regarded as 'hypogonadal' for the male in the context of skeletal health. Much more study is required to define the level of these sex steroids below which bone balance becomes negative, allowing one to predict the development of low bone density.

Other important hormonal factors undergoing intensive investigation include growth hormone and insulin-like growth factor (IGF)-1. Both have been shown to decrease with advancing age, and there is speculation concerning their role in the age-related decrease in of bone density. IGF-1 and one of its important binding proteins, IGF binding protein-3, are positively associated with bone density. IGF-1 levels may be reduced in men with fractures. Moreover, there are important associations between the sex hormones, growth hormone and different growth factors. Nevertheless, growth hormone treatment does not appear to have a conspicuous effect on bone density, nor have there been any fracture studies to assess growth hormone efficacy in healing fractures.

\section{PREVENTION AND TREATMENT OF MALE OSTEOPOROSIS}

Because there are, at present, few evidence-based data from clinical trials with fracture end points, many of the recommendations for the prevention and treatment of male osteoporosis have been extrapolated from guidelines developed for women. It is clear that preventing low bone density and reducing the risk of fracture requires measures to achieve peak bone mass as well as to prevent bone loss and skeletal trauma such as falls. Those at high risk for osteoporosis and fractures because of secondary conditions or high risk lifestyle activities (eg, smoking, excessive alcohol consumption) should be identified. Patients should be counselled about lifestyle modifications. Prudent appropriate exercise should be recommended. While the data concerning calcium and vitamin D supplementation are not definitive, most studies indicate that calcium supplementation may slow down bone loss. Moreover, early in life, an adequate calcium intake is necessary to achieve optimal peak bone density. Although there is no 
absolute consensus concerning the optimal calcium and vitamin D intake, a reasonable approach is to suggest intake of at least 1000 to $1500 \mathrm{mg}$ of elemental calcium per day and 800 to 1000 units of vitamin D. It is thought that these amounts of calcium and vitamin $\mathrm{D}$ are of potential benefit in all elderly individuals, particularly in decreasing the development of secondary hyperparathyroidism and osteomalacia.

Testosterone deficiency plays a central role in the development of osteoporosis, both alone and through its aromatization to estrogen. Hypogonadism is present in some $20 \%$ of men over the age of 60 years and increases significantly with age. About $50 \%$ of men with spine and hip fractures have hypogonadism. Thus, it is important to exclude hypogonadism in all men presenting with osteoporosis and to consider treatment, especially among those with spine and hip fractures, in whom the prevalence is even higher. There have been a paucity of prospective randomized, controlled trials to guide treatment recommendations. But the studies that exist show that testosterone therapy can significantly increase both trabecular and cortical bone density in hypogonadal men (and possibly even eugonadal men) with vertebral crush fractures. Clearly, more studies are required, particularly with fracture end points. However, among men with hypogonadism, testosterone therapy should be offered alone or as adjunctive therapy. The usual contraindications to androgen therapy apply.

Bisphosphonate therapy has been a cornerstone of osteoporosis treatment in women. Although there have been no large, randomized antifracture trials with bisphosphonates in men, a bone density end point trial was recently reported by Orwoll that confirmed the efficacy of alendronate in improving bone density at the spine and the hip. Moreover, in a subanalysis, there was a statistically significant reduction in morphometric vertebral fractures. From this trial and data with other potent bisphosphonates, such as risedronate, the bisphosphonates should be regarded as appropriate treatments for men with either primary or secondary osteoporosis and fractures.

Most of the treatments in use are bone resorption inhibition therapies. On the horizon are exciting possibilities, with bone formation-stimulating treatments, including parathyroid hormone, and possibly other growth factors (eg, growth hormone, analogues of IGF, bone morphogenetic proteins) still in the early stages of development.

\section{CONCLUSIONS}

The importance of osteoporosis in men and the consequences of fragility fractures are now being appreciated as a significant and to date, a relatively neglected, public health concern. While osteoporosis in men and women have many similarities, there are some interesting differences. Bone loss is clearly the result of a bone remodelling imbalance over time, which is not so much due to increased bone resorption as reduced bone formation. Therapies developed by physicians, while not entirely empirical, have been guided by studies in women, and carefully controlled, randomized antifracture clinical trials in men are required. It is clear that hypogonadism is an important causative factor in the development of bone fragility; it should be investigated and treated. While all risk factors should be identified, it is particularly important to eliminate and/or minimize the most common of these, ie, alcohol excess, tobacco use and glucocorticoid therapy.

The rapidly emerging worldwide problem of osteoporosis needs urgent attention. To the same extent, large clinical clinical fracture end points studies are required to guide evidence-based recommendations for prevention and treatment.

\section{BIBLIOGRAPHY}

Amin S, Felson D. Osteoporosis in men. Rheum Dis Clin North Am 2001;27:19-47.

Behre HM. Testosterone therapy - Effects on prostate and bone. Aging Male 2000;3:196-202.

Benagiano G, Maggi S. Osteoporosis in men: An emerging problem. Aging Male 2000;3:59-64.

Cooper C, Atkinson EJ, O'Fallon WM, et al. Incidence of clinically diagnosed vertebral fractures: A population-based study in Rochester, Minnesota, 1985-1989. J Bone Miner Res 1992;7:221-7.

Eastell R, Boyle IT, Compston, et al. Management of male osteoporosis: Report of the UK Consensus Group. QJM 1998;91:71-92.

Melton LJ 3rd, Chrischilles EA. Perspective: How many women have osteoporosis? J Bone Miner Res 1992;7:1005-10.

Nguyen TV, Eisman JA, Kelly PJ, et al. Risk factors for osteoporotic fractures in elderly men. Am J Epidemiol 1996;144:258-61.

O'Neill TW, Felsenberg D, Varlow J, et al. The prevalence of vertebral deformity in European men and women: The European Vertebral Osteoporosis Study. J Bone Miner Res 1996;11:1010-8.

Orwoll E, Ettinger M, Weiss S, et al. Alendronate for the treatment of osteoporosis in Men. N Engl J Med 2000;343:604-10.

Orwoll ES. Osteoporosis in men. Endocrinol Metab Clin North Am 1998;27:349-67.

Seeman E. Osteoporosis in men. Baillieres Clin Rheumatol 1997;11:613-29. 